\title{
Design of Intelligent Temperature Control System for Iron Ore Reduction
}

\author{
Dong $\mathrm{Xie}^{1, \mathrm{a}}$, Jinliang $\mathrm{Shi}^{1}$, Guorong Cheng ${ }^{1, \mathrm{~b}}$, Yunjun $\mathrm{Wu}^{1}$
}

${ }^{1}$ School of Electric \& Information Engineering, Chongqing University of Science and Technology, Chongqing, China

axiedongcq@126.com, ${ }^{b}$ cwcgr@tom.com

Keywords: fuzzy controller, temperature control, parameter self-tuning, Matlab simulink

\begin{abstract}
The precision of temperature control is very important for the iron ore reduction performance test. Due to the conventional PID controller can not be parameter self-tuning on line, this paper proposed that control scheme based on the fuzzy adaptive PID intelligent temperature by combining with fuzzy control technology. By simulating reduction furnace heating and cooling process, it is shown that iron heating rate and heat preservation process achieve good control. Using Matlab fuzzy control toolbox and simulink simulation, the result shows that the self-tuning PID controller has high control precision, small overshoot, good dynamic performance characteristics.
\end{abstract}

\section{Introduction}

With the development of smelting technology for blast furnace, the various thermal performance of iron ore in blast furnace smelting requirements, such as the low temperature, middle temperature and high temperature metallurgical properties is proposed. Iron ore metallurgical property testing content mainly includes reducing, low-temperature reduction and powdering, pellet reducibility and swelling, high temperature softening and melting properties. For the metallurgical properties, the test method is usually used for reduction properties. Experimental method is used to simulate the iron ore heating process in the small reduction furnace. According to the calibration standard, reducing gas is filled into the reduction furnace combining with the oxygen of iron ore. The difficulty level of excluding oxygen is an important quality index to evaluate iron ore metallurgical performance. Reduction performance measurement can be previewed the iron ore performance in the condition of high temperature and has been widely used in the iron ore performance measurement.

A fuzzy controller with adjustable factor is developed on the basic fuzzy controller. In this kind of rule of self-tuning fuzzy controller, using an on-line fuzzy inference algorithm can essentially eliminate steady state error and the chattering phenomenon causing by fuzzy quantization error and adjustment dead of the fuzzy control system. It significantly improves the steady-state performance of fuzzy control system. This design proposes a scheme using single chip computer to realize the reduction furnace temperature control with regulating factor fuzzy control. It is found the advantage of simple hardware circuit, temperature regulating speed and good stability. The simulation results show that the fuzzy controller has very good ability to adapt on the parameters of the controlled object and structure change.

\section{System Hardware Circuit Design}

The temperature control system of $0 \sim 1000^{\circ} \mathrm{C}$ is designed for reduction furnace and its main components include a single-chip STC5410AD, the precision instrumentation amplifier INA114, $\mathrm{A} / \mathrm{D}$ converter and D/A converter. The IGBT power transistor is as heat wire control component, the temperature control system block diagram is seen as Fig.1.

The control system uses the thermocouple as a temperature sensor which has high precision measurement. The thermocouple directly contact with the object, so it is not affected by the intermediate effect. Because of its wide measurement range, the common thermocouple can measure from $-50 \sim+1600^{\circ} \mathrm{C}$ continuously. The thermocouple has good linear relationship between furnace temperatures. 
The precision instrumentation amplifier INA114 with high precision, large range of gain, excellent performance, low price, is very suitable for the use of precision instrument. The system circuit diagram is shown in Fig. 2. While the measured temperature changes, it can output its corresponded value. The terminal connected to the MCU A/D input. By the adjustment factor fuzzy control algorithm, a control volume has been generated by $\mathrm{D} / \mathrm{A}$ converter which can control the switching on and off. The reduction furnace temperature is controlled under the set value.

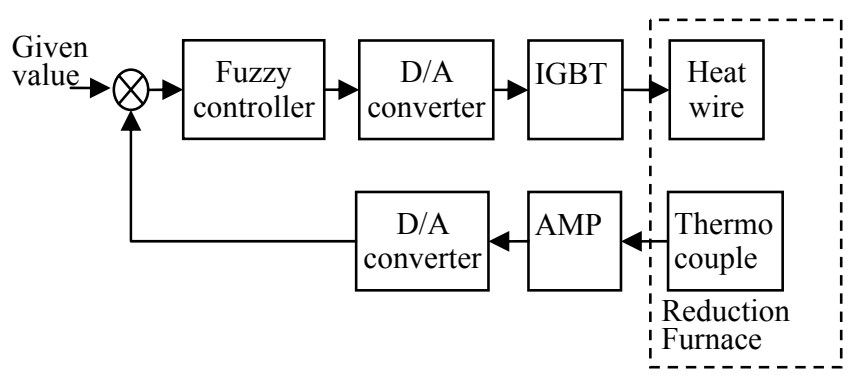

Fig.1 The temperature control system block diagram

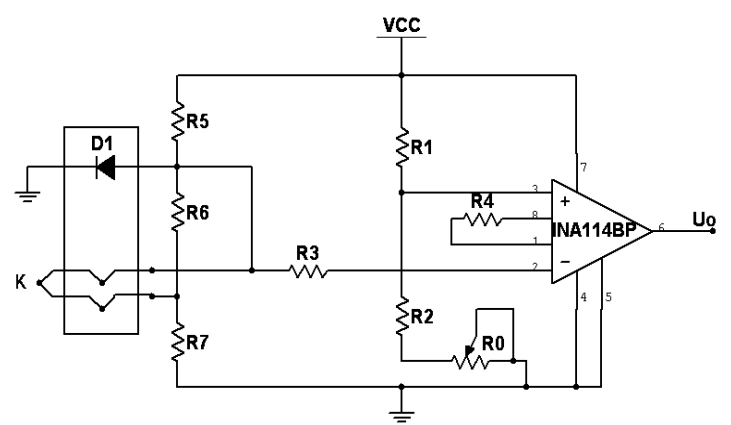

Fig. 2 The system circuit diagram

\section{System Control Requirements}

The first order inertia link with pure lag effect is as ordinary furnace mathematical model, its transfer function is expressed as (1) shown below:

$$
G_{r}(s)=\frac{K_{r}}{T_{i} s+1} e^{-\tau s}
$$

Where, $\mathrm{Kr}$ is gain coefficient which is products of temperature sensor, amplifier, a controllable silicon voltage regulating device and electric proportional coefficient. $\tau$ is system lag time with which related the controlled object. It is noted that (1) applying only to the heating process which the heating element equivalent value is constant. $T_{i}$ is a temperature-dependent value. Formula (1) is shown the object model with the parameter time-varying system at a certain temperature segment.

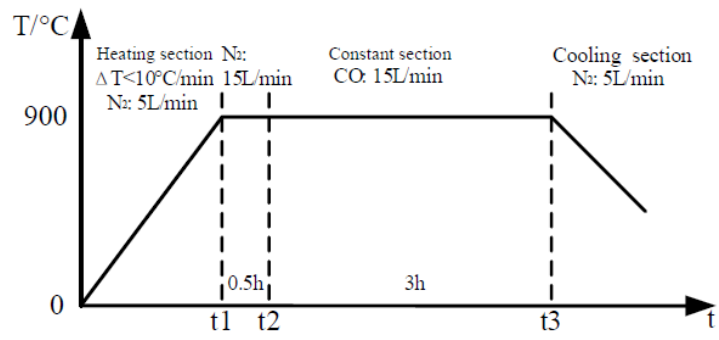

Fig. 3 Temperature variation in iron ore reduction performance measuartion

The iron ore reduction performance measuartion in high temperature is shown in Fig. 3. The sample is restored into the reduction tube. $\mathrm{N}_{2}$ is poured into the reduction tube with standard-state flow $5 \mathrm{~L} / \mathrm{min}$. Then reduction tube is restored into reduction furnace which temperature shall not exceed $200^{\circ} \mathrm{C}$. During start heating, the heating rate shall not exceed $10^{\circ} \mathrm{C} / \mathrm{min}$. When the sample reached $900^{\circ} \mathrm{C}$, the inert gas flow was increased to $15 \mathrm{~L} / \mathrm{min}$ standard state. A constant temperature hold $30 \mathrm{~min}$, poured into deoxidation gas with flow rate of $15 \mathrm{~L} / \mathrm{min}$ replaced inert gas, deoxidate 180min. After reduction gas was cut off, flow $5 \mathrm{~L} / \mathrm{min}$ inert gas were poured into the tube and cooled to $100^{\circ} \mathrm{C}$. Test result is presented by reduction index (Rt) and the reduction rate index (RVI).

\section{Implementation of Fuzzy Control}

The temperature deviation $E$ and temperature deviation change rate $E C$ is as fuzzy control input; the PWM is as output control. The system has no cooling equipment when the temperature exceeds the set value, so the error higher the setting value is not considered. System error and error change rate is shown respectively in following: 


$$
\begin{aligned}
& e(k)=T-T_{0} \\
& e c=e(k)-e(k-1)
\end{aligned}
$$

Where $T$ is furnace current temperature, $T_{0}$ is the set temperature. $E, E C$ and $U$ fuzzy domain are $[0, N]$, quantitative rating are $\{0,1,2, \ldots, N\}$, in domain are used 6 linguistic variables. If errors of $E, E C$ and $U$ have the same classification, the control table can be used the following formula for approximate summary:

$$
U=-\frac{E+E C}{2}
$$

If the formula is introduced into an adjustable factor weighted coefficients $\alpha$ :

$$
U=-[\alpha E+(1-\alpha) E C] \quad \alpha \in(0,1)
$$

By adjusting the value of $\alpha$ can change the error $E$ and error change $E C$ to control output weighted degree and adjust the control rules. For the entire $E$ domain all grades are in accordance with the given weighting coefficients to adjust. When the error is larger, the weight of $E$ is larger in order to eliminate the error and improve response speed as soon as possible. While $E$ decreases, $\alpha$ will decrease. When the error $E$ is small, in order to avoid the system response overshoot, the change of error $E C$ are given higher weighting to enter the state as soon as possible.

\section{Parameter Self-tuning Fuzzy PID Controller Design}

Parameter self-tuning fuzzy PID is designed to make the parameters $K_{p}, K_{i}, K_{d}$ can adjust automatically with deviation $E$ and deviation change rate $E C$. By the experiment and experience, the parameters $\mathrm{K}_{\mathrm{p}}, \mathrm{K}_{\mathrm{i}}, \mathrm{K}_{\mathrm{d}}, E$ and $E C$ in different self-adjustment should meet the following adjustment principle:

(1) If the temperature rises too slowly and its variation is smaller, $K_{p}$ should be increased;

(2) If the temperature rises too fast and hard to reach a stable value, $\mathrm{K}_{\mathrm{i}}$ should be increased;

(3) If the temperature output is fluctuation during stability, $K_{d}$ should be increased;

(4) If the system output is sensitivity to the interference signal, $K_{d}$ should be reduced;

The parameters $\mathrm{K}_{\mathrm{p}}, \mathrm{K}_{\mathrm{i}}, \mathrm{K}_{\mathrm{d}}$ self-tuning is as following step:

a. Determining the input variables and fuzzification. The error $\mathrm{E}$ and $\mathrm{EC}$ error rate is as input variables, fuzzy weight subsets is $\{\mathrm{NB}, \mathrm{NM}, \mathrm{NS}, \mathrm{ZO}, \mathrm{PS}, \mathrm{PM}, \mathrm{PB}\}$, the domain is $\{-6,6\}$.

b. Defining the output variables and membership function. The $K_{p}, K_{i}, K_{d}$ three parameters is as output variable, fuzzy weight subsets is $\{\mathrm{NB}, \mathrm{NM}, \mathrm{NS}, \mathrm{ZO}, \mathrm{PS}, \mathrm{PM}, \mathrm{PB}\}, \mathrm{K}_{\mathrm{p}}$ is on the domain $\{-6,6\}, \mathrm{K}_{\mathrm{i}}$ is $\{-0.6,0.6\}, \mathrm{K}_{\mathrm{d}}$ is $\{-6,6\}$. The triangular membership function is selected.

c. Determining the fuzzy rules. The establishment control rule table is stored in the memory of the microchip. According to the engineering staff of technical knowledge and practical experience, $\mathrm{K}_{\mathrm{p}}, \mathrm{K}_{\mathrm{i}}, \mathrm{K}_{\mathrm{d}}$ three parameters are fuzzy rules are as Table 1:

Table 1 The fuzzy rules of $K_{p}, K_{i}, K_{d}$

\begin{tabular}{|c|l|l|l|l|l|l|l|}
\hline EC & \multirow{2}{*}{$\mathrm{NB}$} & \multirow{2}{*}{$\mathrm{NM}$} & \multirow{2}{*}{$\mathrm{NS}$} & $\mathrm{ZO}$ & $\mathrm{PS}$ & $\mathrm{PM}$ & $\mathrm{PB}$ \\
\hline $\mathrm{NB}$ & $\mathrm{PB} / \mathrm{NB} / \mathrm{PS}$ & $\mathrm{PB} / \mathrm{NB} / \mathrm{NS}$ & $\mathrm{PM} / \mathrm{NM} / \mathrm{NB}$ & $\mathrm{PM} / \mathrm{NM} / \mathrm{NB}$ & $\mathrm{PS} / \mathrm{NS} / \mathrm{NB}$ & $\mathrm{ZO} / \mathrm{ZO} / \mathrm{NM}$ & $\mathrm{ZO} / \mathrm{ZO} / \mathrm{PS}$ \\
\hline $\mathrm{NM}$ & $\mathrm{PB} / \mathrm{NB} / \mathrm{PS}$ & $\mathrm{PB} / \mathrm{NB} / \mathrm{NS}$ & $\mathrm{PM} / \mathrm{NM} / \mathrm{NB}$ & $\mathrm{PS} / \mathrm{NS} / \mathrm{NM}$ & $\mathrm{PS} / \mathrm{NS} / \mathrm{NM}$ & $\mathrm{ZO} / \mathrm{ZO} / \mathrm{NS}$ & $\mathrm{NS} / \mathrm{PS} / \mathrm{ZO}$ \\
\hline $\mathrm{NS}$ & $\mathrm{PM} / \mathrm{NM} / \mathrm{ZO}$ & $\mathrm{PM} / \mathrm{NM} / \mathrm{NS}$ & $\mathrm{PM} / \mathrm{NM} / \mathrm{NM}$ & $\mathrm{PS} / \mathrm{NS} / \mathrm{NM}$ & $\mathrm{ZO} / \mathrm{ZO} / \mathrm{NS}$ & $\mathrm{NS} / \mathrm{PS} / \mathrm{NS}$ & $\mathrm{NS} / \mathrm{PS} / \mathrm{ZO}$ \\
\hline $\mathrm{ZO}$ & $\mathrm{PM} / \mathrm{NM} / \mathrm{ZO}$ & $\mathrm{PM} / \mathrm{NM} / \mathrm{NS}$ & $\mathrm{PS} / \mathrm{NS} / \mathrm{NS}$ & $\mathrm{ZO} / \mathrm{ZO} / \mathrm{NS}$ & $\mathrm{N} / \mathrm{PS} / \mathrm{NS}$ & $\mathrm{NM} / \mathrm{PM} / \mathrm{PS}$ & $\mathrm{NM} / \mathrm{PM} / \mathrm{ZO}$ \\
\hline $\mathrm{PS}$ & $\mathrm{PS} / \mathrm{MS} / \mathrm{ZO}$ & $\mathrm{PS} / \mathrm{MS} / \mathrm{ZO}$ & $\mathrm{ZO} / \mathrm{ZO} / \mathrm{ZO}$ & $\mathrm{NS} / \mathrm{PS} / \mathrm{ZO}$ & $\mathrm{NS} / \mathrm{PS} / \mathrm{ZO}$ & $\mathrm{NM} / \mathrm{PM} / \mathrm{ZO}$ & $\mathrm{NM} / \mathrm{PB} / \mathrm{ZO}$ \\
\hline $\mathrm{PM}$ & $\mathrm{PS} / \mathrm{ZO} / \mathrm{PB}$ & $\mathrm{ZO} / \mathrm{ZO} / \mathrm{NS}$ & $\mathrm{NS} / \mathrm{PS} / \mathrm{PS}$ & $\mathrm{NM} / \mathrm{PS} / \mathrm{PS}$ & $\mathrm{NM} / \mathrm{PM} / \mathrm{PS}$ & $\mathrm{NM} / \mathrm{PB} / \mathrm{PS}$ & $\mathrm{NB} / \mathrm{PB} / \mathrm{PB}$ \\
\hline $\mathrm{PB}$ & $\mathrm{ZO} / \mathrm{ZO} / \mathrm{PB}$ & $\mathrm{ZO} / \mathrm{ZO} / \mathrm{PM}$ & $\mathrm{NM} / \mathrm{PS} / \mathrm{PM}$ & $\mathrm{NM} / \mathrm{PM} / \mathrm{PM}$ & $\mathrm{NB} / \mathrm{PB} / \mathrm{PS}$ & $\mathrm{NB} / \mathrm{PB} / \mathrm{PS}$ & $\mathrm{NB} / \mathrm{PB} / \mathrm{PB}$ \\
\hline
\end{tabular}

d. On-line parameter self-adjusting. To meet the needs of different $E$ and $E C$ parameters of the controller's requirements, the fuzzy matrix table is designed according to the fuzzy synthesis interfere PID parameter, correction parameter is calculated:

$$
K p \quad . K p^{*} \quad K p, \quad K i . K i^{*} \quad K i, \quad K d . K d^{*} \quad K d
$$

Where, $K_{p}, K_{i}, K_{d}$ is PID control parameters, $K_{p}{ }^{*}, K_{i}^{*}, K_{d}{ }^{*}$ is the PID parameter datum $\Delta K_{p}, \Delta K_{i}$, $\Delta K_{d}$ is PID parameter correction values. 


\section{MATLAB Simulation}

The various control system toolbox including fuzzy logic toolbox, simulink and utility toolbox are applied to system simulation research. In the Matlab command window we input fuzzy inference system, which is mainly used for the design and display of fuzzy inference system.

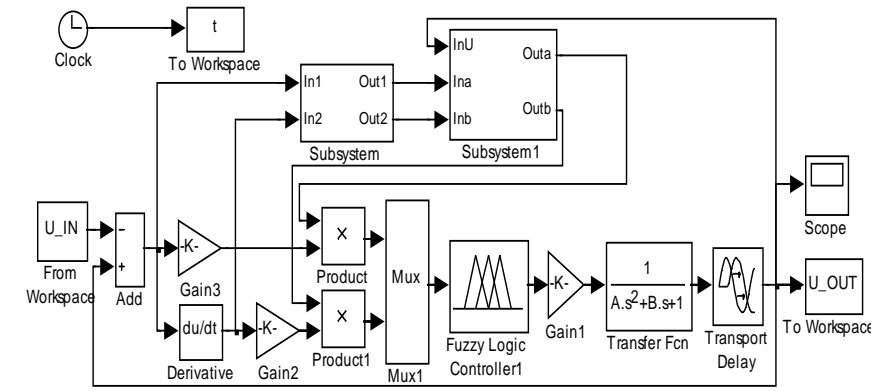

Fig. 4 Block diagram of fuzzy controller

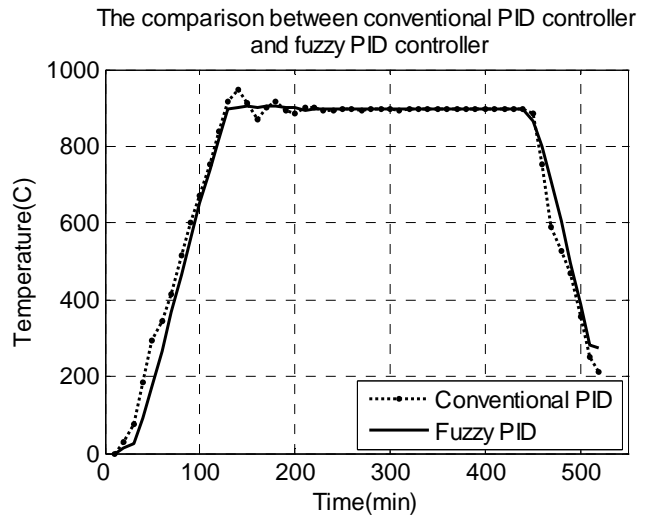

Fig. 5 The simulation results in simulink

Using the fuzzy toolbox, the fuzzy control system of $E, E C$ double input, $\mathrm{K}_{\mathrm{p}}, \mathrm{K}_{\mathrm{i}}, \mathrm{K}_{\mathrm{d}}$ three output is built. The parameters self-tuning principle and the construction of the membership function and control rules in Matlab environment is used to realization of the simulation study. The parameter self-tuning PID simulation block diagram is as Fig.4. The fuzzy PID controller and the conventional PID controller simulation results are shown in Fig. 5.

\section{Conclusions}

This paper introduces the design of a self-tuning PID temperature fuzzy controller. The simulation curve can be seen that this control system has good dynamic performance and static performance than the conventional PID controller. It can be seen that the parameter self-tuning PID controller has higher control precision and fast dynamic response, small overshoot and other advantages. It can overcome the traditional fuzzy control some disadvantage which easy to appear the cyclical fluctuations near the given value, poor tracking and anti-jamming performance.

\section{Acknowledgements}

This research is supported by Chongqing Science and Technology Research Projects (No.cstc2011pt-gc70007, cstc2012gg-yyjs0118), national natural sciences fund of China (NO. 51275547), the achievements support Foundation of Chongqing Municipal Education Commission (No. kjzh11221, kj121413, 201028), and Research Foundation of Chongqing University of Science \& Technology (No. CK2010Z10, CK2011B01).

\section{Reference}

[1]P. Cominos, N. Mnro: Proceedings of Control Theory IEEE \& Application, Vol.149(2002), p.46 [2]S.Y. Li: Fuzzy control, neural control and intelligent control theory (Harbin Industry University Press, 1998) (In Chinese)

[3]L. Shi: Journal of Zhengzhou University of technology, Vol.22(2001), p.25 (In Chinese)

[4]J.P. Hu: Journal of Shanghai University of Engineering Science, Vol.20(2006), p.65 (In Chinese)

[5]W.Wang, J.T.Zhang and T.Y.Chai: Journal of Automation,Vol.26 (2000),p.347(In Chinese)

[6]Y.F. Shen, S.J. Wu and F.L. Deng: Industrial Instrumentation \& Automation, Vol.6(2002), p.11(In Chinese) 